\title{
Importance of Cognitive Screening and Management in Multiple Sclerosis Care-Reflection on the Recent Recommendations
}

An Expert Interview with Rosalind Kalb

National Multiple Sclerosis Society, New York, NY, US

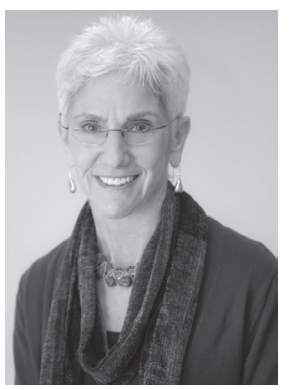

DOI: https://doi.org/10.17925/USN.2018.14.2.73

\section{Rosalind Kalb}

Rosalind Kalb, PhD, is a clinical psychologist who has specialized in multiple sclerosis (MS) care and education for over 30 years. After receiving her doctorate from Fordham University in 1977, she began her career in MS, providing individual, group, and family therapy at the Medical Rehabilitation Research and Training Center for MS at the Albert Einstein College of Medicine and then at the MS Comprehensive Care Center in White Plains, NY. Dr Kalb joined the National MS Society in 2000, creating online resources and educational materials for individuals and families living with MS and healthcare professionals until 2017. She continues her resource development work for the Society as a consultant and also serves as Senior Programs Consultant for 'Can Do Multiple Sclerosis'. Dr Kalb is senior author of Multiple Sclerosis for Dummies (2nd ed.), and co-author of Multiple Sclerosis: Understanding the Cognitive Challenges. In addition, Dr Kalb has edited two books: Multiple Sclerosis: The Questions You Have; The Answers You Need, now in its 5 th edition, and Multiple Sclerosis: A Guide for Families, now in its 3rd edition.

\section{Keywords}

Multiple sclerosis, recommendations, care, cognition, cognitive dysfunction, screening, treatment, rehabilitation, management

Disclosure: Rosalind Kalb is lead author of the article that is the focus of this interview, and is a member of the journal's editorial board.

Review Process: This is an expert interview and, as such, has not undergone the journal's standard peer review process.

Authorship: The named author meets the International Committee of Medical Journal Editors (ICMJE) criteria for authorship of this manuscript, takes responsibility for the integrity of the work as a whole, and has given final approval for the version to be published.

open Access: This article is published under the Creative Commons Attribution Non-commercial License, which permits any non-commercial use, distribution, adaptation, and reproduction provided the original author and source are given appropriate credit. (c) The Author 2018.

Received: October 8, 2018

Published Online: November 6, 2018

Citation: US Neurology. 2018;14(2):73-5

Corresponding Author: Rosalind Kalb,

290 Sabino Road, West Bath, ME 04530, US.

E: rosalind.kalb@nmss.org

Support: No funding was received in

the publication of this article.
$\mathrm{T}$ he importance of recognizing and including cognition as a key factor to consider when ensuring comprehensive care for individuals with multiple sclerosis (MS) cannot be over emphasized. Unfortunately, despite it being accepted as a common symptom, cognitive function in MS is still not openly discussed, routinely assessed, or optimally treated. In an expert interview, Rosalind Kalb describes the background and crucial recent steps taken to tackle this issue, starting with a convening of the National MS Society's National Medical Advisory Committee and leading to published recommendations for cognitive screening and management in MS care.

\section{Q. Why did the National Medical Advisory Committee of the National MS Society commission this group of experts to make recommendations based on the published literature about the management of MS-related cognitive impairment?}

As the evidence continued to mount concerning the prevalence and impact of cognitive impairment on individuals and families affected by MS, the Society committed itself to addressing the need for early and ongoing assessment and management of cognitive symptoms. The Society's National Medical Advisory Committee convened an interdisciplinary group of clinicians and researchers, as well as people with MS, to make recommendations ${ }^{1}$ based on the published literature and their professional expertise and personal experiences.

\section{Q. What do we know about the prevalence of cognitive impairment in people with MS?}

At least 65\% of people with MS are going to experience some degree of cognitive impairment. ${ }^{2,3}$ This common MS symptom is most prevalent in people with progressive disease, ${ }^{4,5}$ but it also occurs in people with relapsing MS, clinically isolated syndrome, ${ }^{6,7}$ and radiologically isolated syndrome. ${ }^{8}$ In fact, it appears to predate the appearance of structural abnormalities on magnetic resonance imaging and may serve as an early marker of disease activity., 
Like all symptoms of MS, however, cognitive impairment is highly variable from one person to another. One person may experience no difficulties at all, while others may experience moderate or more severe impairments that impact many areas of their lives.

\section{Q. What are the most common types of cognitive changes that occur?}

Information processing and memory are the most commonly affected cognitive domains in MS. Other cognitive symptoms include deficits in complex attention, executive functioning, verbal fluency, visuospatial perception, and social cognition. 9,10 In other words, cognitive functioning in people with MS can be impaired in many different ways. Slowed information processing speed is considered the hallmark cognitive deficit in MS. As the foundation for higher-level cognitive processes, slowed processing impacts virtually all other cognitive domains. ${ }^{11}$

\section{Q. What are some of the ways that cognitive impairment impacts daily functioning at work and home, relationships, and quality of life?}

Cognitive impairment predicts limitations in the workplace and in social settings independent of level of physical disability. ${ }^{12-15}$ In fact, cognitive impairment at diagnosis predicts a change in vocational status 7 years later. Compared with healthy controls, people with MS perform more poorly on everyday life tasks, including driving and money management, ${ }^{16-19}$ and cognitive impairment in children and teens is associated with slowed cognitive development, problems in school, social challenges, and depression. ${ }^{20,21}$ People who are cognitively impaired also have difficulty engaging in shared decision making, providing informed consent, and adhering to treatment. .22,23 $^{2}$

Support partners and other family members are significantly affected by their loved ones' cognitive changes. MS caregivers experience high levels of distress, depression, and a reduced quality of life related to their partners' cognitive impairment and psychiatric symptoms - even beyond that related to their physical symptoms. ${ }^{24}$ And along with bladder/bowel dysfunction and impaired mobility, challenges related to cognitive impairment may predict nursing home placement for people with $\mathrm{MS}^{25}$

\section{Q. What are the goals of your recent publication in relation to this?}

The goals of the paper ${ }^{1}$ are to promote awareness and understanding of cognitive impairment in MS; reduce any associated stigma; recommend optimal screening, monitoring, and treatment strategies; and address barriers to optimal management.

\section{Q. What are the Society's recommendations for assessment and management?}

The Society recommendations are very specific. ${ }^{1}$ For adults and children 8 years of age and older:

- As a minimum, early baseline screening with the Symbol Digit Modalities Test (SDMT) or similarly validated test, when the patient is clinically stable.
- Annual re-assessment with the same instrument, or more often as needed to: (a) detect acute disease activity; (b) assess for treatment effects (e.g., when starting/changing a disease-modifying therapy) or for relapse recovery; (c) evaluate progression of cognitive impairment; and/or (d) screen for new-onset cognitive problems.

For adults 18 years of age and above: more comprehensive assessment for anyone who tests positive on initial cognitive screening or demonstrates significant cognitive decline, especially if there are concerns about comorbidities or the individual is applying for disability due to cognitive impairment.

For children below 18 years of age: neuropsychological evaluation for any unexplained change in school functioning (academic or behavioral).

Remedial interventions/accommodations for adults and children to improve functioning at home, work or school.

\section{Q. Can you comment on factors, other than the disease itself, that can impact cognition?}

Sleep disturbances, mood changes and fatigue-all of which are common in people with MS - can significantly impact cognitive functioning. ${ }^{26-30}$ For these reasons, people with MS should be screened annually for depression and asked on a regular basis about their sleep. In addition, some of the medications commonly used by people with MS, including anticholinergic medications to treat bladder dysfunction, can slow information processing and impair memory. ${ }^{31}$ Since polypharmacy, which can increase fatigue and impact cognition, is common in people with MS, healthcare providers are encouraged to review a patient's medications on a regular basis. ${ }^{32}$ And because cannabis smokers show slowed processing speed and reduced memory compared with non-cannabis smokers, patients should be advised of this risk. ${ }^{33-36}$

\section{Q. What are some of the barriers to optimal care for this common MS symptom?}

The primary barriers include: insufficient knowledge on the part of people with MS, family members, and healthcare providers about the prevalence and impact of cognitive dysfunction or the available screening, assessment, and management strategies; reluctance on the part of clinicians (due to shortage of time, lack of expertise or referral sources, or inadequate reimbursement) and patients (due to embarrassment or concerns that cognitive problems might affect their employment, child custody, or driver's license) to address the issue; and insufficient numbers of clinicians are trained to provide assessment and remediation.

\section{Q. What strategies are recommended for addressing these barriers and what steps is the Society taking to implement these strategies?}

The Society convened three work teams in 2018 to identify and implement short- and longer-term strategies to address these barriers. The Awareness Team is determining optimal strategies for promoting awareness among professional and lay audiences of the prevalence and impact of cognitive impairment. The Screening in the Clinic Team 
is working to promote and facilitate early and ongoing screening in the neurology clinic. The Professional Education Team is developing online and in-person training opportunities for licensed, certified speech/language pathologists, occupational therapists, psychologists, and other clinicians who would like to treat people with MS. Toolkits for each audience will provide essential information about cognition in MS as well as information about screening and assessment measures and ways to identify trained clinicians in the community.

\section{Q. What is the key take-away message about cognitive care in MS?}

Identification and management of cognitive symptoms is an essential component of comprehensive MS care. Although the current barriers to optimal care must be acknowledged and overcome, doing nothing in the meantime to address cognitive challenges among people living with MS is not acceptable.
1. Kalb R, Beier M, Benedict RH, et al. Recommendations for cognitive screening and management in multiple sclerosis care. Mult Scler. 2018. DOI: 10.1177/1352458518803785 [Epub ahead of print]. Available at: https://doi.org/10.1177/1352458518803785 (accessed November 2, 2018)

2. Achiron A, Chapman J, Magalashvili D, et al. Modeling of cognitive impairment by disease duration in multiple sclerosis: cross-sectional study. PloS One. 2013;8:371058.

3. Johnen A, Landmeyer NC, Bürkner P-C, et al. Distinct cognitive impairments in different disease courses of multiple sclerosis. A systematic review and meta-analysis. Neurosci Biobehav Rev. 2017:83:568-78.

4. Gouveia A, Dias SP, Santos T, et al. Cognitive impairment and magnetic resonance imaging correlates in primary progressive multiple sclerosis. Acta Neurol Scand. 2017;136:109-15.

5. Ruano L, Portaccio E, Goretti B, et al. Age and disability drive cognitive impairment in multiple sclerosis across disease subtypes. Mult Scler. 2017;23:1258-67.

6. Hynčicová E, Vyhnálek M, Kalina A, et al. Cognitive impairment and structural brain changes in patients with clinically isolated syndrome at high risk for multiple sclerosis. J Neurol. 2017:264:482-93.

7. Diker S, Has AC, Kurne A, et al. The association of cognitive impairment with gray matter atrophy and cortical lesion load in clinically isolated syndrome. Mult Scler Relat Disord 2016;10:14-21

8. Labiano-Fontcuberta A, Martínez-Ginés ML, Aladro Y, et al. A comparison study of cognitive deficits in radiologically and clinically isolated syndromes. Mult Scler. 2016:22:250-3.

9. Benedict RHB, Fischer JS, Archibald CJ, et al. Minimal neuropsychological assessment of MS patients: a consensus approach. Clin Neuropsychol. 2002;16:381-97.

10. Chiaravalloti ND, DeLuca J. Cognitive impairment in multiple sclerosis. Lancet Neurol. 2008;7:1139-51.

11. Denney DR, Lynch SG, Parmenter BA. A 3-year longitudinal study of cognitive impairment in patients with primary progressive multiple sclerosis: speed matters. J Neurol Sci. 2008;267:129-36.

12. Rao $\mathrm{SM}$, Leo GJ, Ellington $\mathrm{L}$, et al. Cognitive dysfunction in multiple sclerosis. Il. Impact on employment and social functioning. Neurology. 1991;41:692-6.
13. Ruet A, Deloire M, Hamel D, et al. Cognitive impairment, health-related quality of life and vocational status at early stages of multiple sclerosis: a 7-year longitudinal study. J Neurol. 2013;260:776-84

14. Papathanasiou A Messinis L, Zampakis P. Papathanasopoulos P. Corpus callosum atrophy as a marker of clinically meaningful cognitive decline in secondary progressive multiple sclerosis. Impact on employment status. J Clin Neurosci. 2017;43:170-5.

15. Campbell J, Rashid W, Cercignani M, et al. Cognitive impairment among patients with multiple sclerosis: associations with employment and quality of life. Postgrad Med J. 2017:93: $143-7$.

16. Dehning M, Kim J, Nguyen $\mathrm{CM}$, et al. Neuropsychological performance, brain imaging, and driving violations in multiple sclerosis. Arch Phys Med Rehabil. 2014;95:1818-23.

17. Morrow SA, Classen S, Monahan M, et al. On-road assessment of fitness-to-drive in persons with MS with cognitive impairment: A prospective study. Mult Scler. 2018;24:1499-506.

18. Goverover Y, Haas S, DeLuca J. Money management activities in persons with multiple sclerosis. Arch Phys Med Rehabi. 2016;97:1901-7.

19. Tracy VL, Basso MR, Marson DC, et al. Capacity for financial decision making in multiple sclerosis. $J$ Clin Exp Neuropsychol. 2017;39:46-57

20. Charvet LE, O'Donnell EH, Belman AL, et al. Longitudinal evaluation of cognitive functioning in pediatric multiple sclerosis: report from the US Pediatric Multiple Sclerosis Network. Mult Scler. 2014;20:1502-10.

21. Mikaeloff Y, Caridade G, Billard C, et al. School performance in a cohort of children with CNS inflammatory demyelination. Eur J Paediatr Neurol. 2010:14:418-24.

22. Bruce JM, Hancock LM, Arnett P, et al. Treatment adherence in multiple sclerosis: association with emotional status, personality, and cognition. J Behav Med. 2010;33:219-27.

23. Gerstenecker A, Lowry K, Myers T, et al. Medical decision-making capacity and its cognitive predictors in progressive MS: Preliminary evidence. J Neurol Sci. 2017; 380:38-43.

24. Figved N, Myhr K-M, Larsen J-P, et al. Caregiver burden in multiple sclerosis: the impact of neuropsychiatric symptoms. J Neurol
Neurosurg Psychiatry. 2007;78:1097-102.

25. Thorpe LU, Knox K, Jalbert R, et al. Predictors of institutionalization for people with multiple sclerosis. Disabil Health J. 2015;8: $271-77$

26. Hughes AJ, Parmenter BA, Haselkorn JK, et al. Sleep and its associations with perceived and objective cognitive impairment in individuals with multiple sclerosis. J Sleep Res. 2017:26:428-35.

27. Patel VP, Walker LAS, Feinstein A. Processing speed and distractibility in multiple sclerosis: the role of sleep. Mult Scler Relat Disord. 2017;11:40-2.

28. Braley TJ, Kratz AL, Kaplish N, et al. Sleep and cognitive function in multiple sclerosis. Sleep. 2016;39:1525-33.

29. Portaccio E. Differential diagnosis, discerning depression from cognition. Acta Neurol Scand. 2016;134 (Suppl 200):14-8.

30. Morrow SA, Rosehart H, Pantazopoulos K. Anxiety and depressive symptoms are associated with worse performance on objective cognitive tests in MS. J Neuropsychiatry Clin Neurosci. 2016;28:118-23.

31. Cruce R, Vosoughi R, Freedman MS. Cognitive impact of anticholinergic medication in MS: Adding insult to injury? Mult Scler Relat Disord. 2012;1:156-61.

32. Thelen JM, Lynch SG, Bruce AS, et al. Polypharmacy in multiple sclerosis: relationship with fatigue, perceived cognition, and objective cognitive performance. J Psychosom Res. 2014;76:400-4.

33. Feinstein A, Banwell E, Pavisian B. What to make of cannabis and cognition in MS: In search of clarity amidst the haze. Mult Scler. 2015;21:1755-60.

34. Pavisian B, Staines WR, Feinstein A. Cannabis-induced alterations in brain activation during a test of information processing speed in patients with MS. Mult Scler J Exp Trans/ Clin. 2015:1:2055217315588223

35. Pavisian B, Maclntosh BJ, Szilagyi G, et al. Effects of cannabis on cognition in patients with MS: a psychometric and MRI study. Neurology. 2014;82:1879-87.

36. Romero K, Pavisian B, Staines WR, Feinstein A. Multiple sclerosis, cannabis, and cognition: A structural MRI study. Neuroimage Clin. 2015:8:140-7. 